of standardized summaries which could be circulated to editors in various countries.

Professor P. Milliez (Paris), speaking as an author, said that very often he had been "betrayed" by journals which had summarized his papers in a foreign language and which had not been a true reproduction of what he had written in the original.

Dr. Mario Cardia (Oporto: Médico) said that he represented a weekly journal which did everything possible to publish as many summaries in translation as was practicable, but there was a serious financial problem to be faced. Summaries in French, and very often in English, of all original articles were published in his journal. Special issues of the journal were devoted to the medicine of other countries.

Dr. D. Crowther (London: Abstracts of World Medicine) pointed out that a translation might be academically perfect, yet, by the choice of the wrong word, might convey shades of meaning which were not intended in the original.

\section{SOCIAL OCCASIONS}

On the evening before the congress began the British Medical Journal held a reception for the delegates at B.M.A. House. About 200 guests attended this "get-together" party, and they were received by Dr. and Mrs. H. A. Clegg and by Dr. J. G. M. Hamilton, chairman of the Journal Committee of the British Medical Association, and Mrs. Hamilton. On September 13 half the delegates were entertained at a luncheon held by invitation of the Royal College of Surgeons and of Sir Cecil Wakeley, editor of the Annals of the Royal College of Surgeons, and the other half at a luncheon held by invitation of the Ciba Foundation. In the evening the Practitioner gave a dinner at the Royal College of Surgeons. Sir Heneage Ogilvie genially welcomed the visitors in a short speech, saying how delightful it was to see so many people of such distinction representing so many journals, and how fitting it was for an international gathering to meet together in the Hall of the Royal College of Surgeons, which itself represented a triumph of reason over destruction. Dr. Joseph Garland, editor of the New England Journal of Medicine, and Dr. A. Plichet, editor of the Presse Médicale, spoke briefly in reply. On September 14 the Lancet invited the delegates to a fork luncheon at 7, Adam Street.

On the evening of September $14 \mathrm{a}$ banquet was given by the British Medical Journal in the Great Hall of B.M.A. House. After the loyal toast had been honoured, Lord Cohen of Birkenhead, a Vice-President of the British Medical Association, proposed the health of the Union Internationale de la Presse Médicale. Speaking of medical journals generally, he said they had an indispensable place in the postgraduate education of the doctor. As to editorial responsibility, he was quite certain that it should be absolute and sacrosanct: he would support that view to the death. Mentioning the question of professional anonymity, Lord Cohen of Birkenhead said that this was a problem needing careful reconsideration now that such instruments existed for the dissemination of knowledge as the radio and television. In conclusion he spoke of the charm and selflessness of Dr. A. Plichet, whose name he linked with the toast. In reply, Dr. Plichet expressed his pleasure at the outcome of the congress and thanked Lord Cohen, the British Medical Association, and all those who had contributed to the success of the meeting. The Union had grown, he said, from small beginnings, and now had members all over the world. All members were united in holding the highest standards of accuracy and objectivity, which lay at the heart of scientific and medical journalism. The medical press had a very special contribution to make at the present time. "Nous contribuons, ainsi, à édifier, à sauvegarder, et à enrichir le patrimoine scientifique de nos pays, de tous les pays, et nous aussi, nous écrivons l'histoire."

On Sunday, September 15 , nearly 80 of the delegates made a whole-day trip to Cambridge. Luncheon and tea were taken in the hall of Trinity College, by kind permission of the Master, Lord Adrian, O.M.

\section{Correspondence}

Because of heavy pressure on our space, correspondents are asked to keep their letters short.

\section{Palliative Radiotherapy}

SIR,-I would like to congratulate you on your leading article on palliative radiotherapy (Journal, August 24, p. 455), which I feel sure was welcomed by all who have to assist in the management of patients suffering from advanced cancer of either the breast or lung. I would, however, like to say a few words about the suggestion made in the last sentence, that there has been an increase in fibrosis of the lung since super-voltage therapy became more generally available. For some time I have been particularly interested in fibrosis of the lung following conventional deep $x$-ray therapy for carcinoma of the breast, and have been able to show ${ }^{1}$ that the great majority of patients treated by this method to high dosage subsequently develop some degree of post-radiation fibrosis of the underlying lung. In Newcastle we have used the $4 \mathrm{meV}$ linear accelerator in the treatment of patients for over three years, and our experience is that the local and general complications of the treatment are less severe than with conventional $x$-ray therapy apparatus. In the treatment of carcinoma of the breast, the use of super-voltage radiotherapy to treat either the chest wall or the regional lymph node areas appears to reduce the incidence of subsequent post-radiation fibrosis to about one-third of what it is with conventional therapy. I would be grateful if you would publish this letter, which may help to avoid misleading impressions about the possible effects of irradiation being held by general practitioners and consultants in other specialties.-I am, etc.,

$$
\begin{aligned}
& \text { Newcastle upon Tyne, } 1 . \quad \text { William M. Ross. } \\
& { }^{1} \text { Thorax, 1956, 11, } 241 .
\end{aligned}
$$

\section{Dietary Fat and Coronary Disease}

SIR,-There seems to be an assumption in your leading article on this subject (Journal, July 13, p. 89) which requires qualification. It is assumed that "faster blood coagulation" has a bearing on the problem of coronary thrombosis. Leaving aside the question of what relationship, if any, exists between the highly artificial conditions of in vitro coagulation of blood and intravascular clotting, is there any evidence to suggest that a clot which forms in a few seconds has more serious consequences than one taking hours, unless the activity of the fibrinolytic mechanism at the same time is considered?

I believe that insufficient attention has been paid to the activity of the fibrinolytic mechanism of the blood and the effect of dietary fats and blood lipids on this mechanism. We have shown that in vitro fibrinolysis is inhibited by fatty meals ${ }^{1}$ and more recently ${ }^{2}$ that, of a variety of fats tested, only butter fat and egg yolks were inhibitory, vegetable oils being generally without effect or appearing to activate fibrinolytic activity. The difficulty of assessing the validity of in vitro studies to in vivo conditions applies also to in vitro fibrinolysis, but at all events techniques have been developed to study in vivo fibrinolysis. ${ }^{3}$

Using such techniques Kwaan and MacFadzean* have been able to demonstrate inhibition of in vivo fibrinolysis in rabbits fed cholesterol. Care is always necessary, of course, in the projection of experimental results obtained in one species to another species, and in this connexion it is perhaps worthy of note that heparin parenterally does not cause activation of fibrinolysis in the rabbit, although a small dose $(0.3 \mathrm{mg}$. per $\mathrm{kg}$. body weight intravenously) is sufficient to cause marked, if transient, activation of fibrinolysis in man. This effect of heparin in man we attribute to activation of the lipaemia "clearing reaction" (really a breaking down of lipo-proteins). This and other evidence suggests to me that the inhibitory substances to fibrinolysis in plasma are lipoproteins. $^{2}$ 
A further observation of interest is that an increase in the plasma of material metachromatically reacting with azure $\mathbf{A}$ is associated with alimentary lipaemia. This may or may not be heparin (we have not yet identified it), but it is bound to lipo-protein and usually cannot be detected in native plasma (cf. heparin, according to Jaques ${ }^{5}$ ) but only in plasma after ether-extraction in the cold (below $-25^{\circ} \mathrm{C}$.). The relationship of this metachromatic material to heparin and/or heparin-activated "clearing factor" is a matter for further study.

The appearance of this material in the plasma makes me wonder if there is not perhaps a link between this observation and that of Shoulders and Meng. ${ }^{6}$ These workers found that intraperitoneal injection of lipid emulsions caused disruption of the peritoneal mast cells. The active factor was possibly a phosphatide. It is tempting to speculate whether the effect of alimentary lipaemia on the mast cells of the blood vessel walls may not be similar, with a release of metachromatically reacting substances into the plasma. It may depend on the composition of the chylomicrons and lipoproteins composing the lipaemia, especially in respect of phosphatides, whether such material is released. An analogy may perhaps be seen to the non-specific serum inhibitor of hyaluronidase of Glick, ${ }^{7}$ which is apparently a heparinlipoprotein complex, believed to be derived from the mast cell. Indeed, certain similarities of behaviour raise the question whether these inhibitors may not be identical.

It is my belief that the "non-specific" lipoprotein inhibitors of enzymes (especially proteases) play vital roles in many physiological processes ranging from the fertilization of the egg to the control of protein synthesis in the cell. I think these observations and speculations may have a bearing on the pathogenesis of coronary thrombosis and the role of dietary fats therein and are put forward to stimulate discussion and to attempt to suggest directions other than the old, very well-worn paths along which research on this subject is largely being pursued.-I am, etc.,

Johannesburg, S. Africa.

H. B. W. Greig.

1 Greig. H. B W., Lancet, 1956, 2, 16.

2 and Runde, I. A., Lancet, in press.

- Grossi, C. E., Cliffton, E. E., and Cannamela, D. A., Blood, 1954, 9, 310. - Kwaan, H. C., and MacFadzean, A. J. S., Nature (Lond.), 1957, 179. 260.

- Jaques, L. B., in The Coagulation of Blood, 1955, edited by L. M. Tocantins, p. 206 . Grune and Stratton, N.Y.

- Shoulders, H. H., and Meng, H. C., Fed. Proc., 1957, 16, 371.

7 Glick, D., and Sylvén, B., Srience, 1951, 113, 388.

\section{Relief of Stokes-Adams Syndrome after Cholecystectomy}

SIR,-Physiologists have noted a reflex mechanism from gall-bladder to heart. This mechanism may account for auricular fibrillation. Anginal pain sometimes seems to be triggered off by a diseased gall-bladder, and Gilbert ${ }^{1}$ produced a variety of arrhythmias in dogs by distending the gall-bladder and other abdominal viscera. Buchbinder ${ }^{2}$ found that experimentally produced sudden alterations of pressure in the gall-bladder of frogs cause asystole and sinus bradycardia by a vagal reflex, which atropine and section of the vagus abolished. From these experimental and clinical observations it is apparent that the gall-bladder may play some role in some disturbances of cardiac mechanism.

In 1955 McLemore and Levine, ${ }^{3}$ of Harvard Medical School, published reports of seven patients who had typical attacks of Stokes-Adams syncope. All had gallstones, and cholecystectomy was performed in every case. In every instance the number of attacks decreased after the operation, the purpose of which was to abolish the action on the heart of the trigger-like mechanism of a diseased gall-bladder. It appears that cholecystectomy is tolerated satisfactorily by patients with complete heart block. These reports indicate that gallstones should be searched for carefully in all cases of Stokes-Adams disease. The following case report bears this out.

A married woman, aged 51, was first seen in March, 1952, when she was unconscious from a Stokes-Adams attack. She had had minor attacks of fainting for three months, but no total unconsciousness. Her pulse rate was between 30 and $40 / \mathrm{min}$., and regular, the heart was enlarged, and the blood pressure considerably raised. An E.C.G. showed no gross abnormality. Within three days her pulse rate was back to $72 / \mathrm{min}$. During the following three years she had many minor attacks of transient fainting. She was never really well, could only do her housework with difficulty, and was afraid to leave her home. She had almost continuous headaches, but she noticed that these left her during her attacks of fainting. Her blood pressure was in the region of $180 / 120 \mathrm{~mm} . \mathrm{Hg}$ and it was presumed that her headaches were hypertensive in nature.

In 1956 the patient's attacks became worse. On September 9, 1956, I saw her when she was regaining consciousness after a major attack, during which she also had vomited. Within five minutes she lapsed once more into deep unconsciousness, there was a period of apnoea, the pulse disappeared, she became cyanosed, and the pupils dilated. Rhythmic pressure via the diaphragm was applied and continued for a short while after she had regained consciousness. Whenever the gall-bladder region was touched a distinct expression of pain was noticeable even before she had become fully conscious. She entered hospital with a pulse rate of $12-16 / \mathrm{min}$. The E.C.G. showed incomplete irregular heart block. She improved rapidly on ephedrine sixhourly, and was discharged on this regime. In spite of medication her pulse rate was mostly in the region of $40 / \mathrm{min}$. She was having many minor attacks again which once more brought diminution of her headaches while they lasted. The gall-bladder was now distinctly palpable and very tender to touch. Surgical opinion was then sought, and on December 20 cholecystectomy was carried out and one large and several smaller stones were found in the gall-bladder. Recovery was uneventful and no ephedrine was administered during the convalescence. Since the operation until to date- that is, for the past seven months-the patient has had neither major nor minor attacks of Stokes-Adams syndrome. She has had no medication whatsoever, apart from mild analgesics for her headaches, which since the operation, probably due to a now uninterrupted high blood pressure, have become a more or less permanent fixture. Her pulse is constantly in the region of $70 / \mathrm{min}$.

My thanks are due to Dr. C. Astley and Mr. S. Mottershead, of North Ormsby Hospital, Middlesbrough, for their help with this case.-I am, etc., Middlesbrough.

\section{REFERENCES}

J. Abels.

${ }^{1}$ Gilbert, N. C., Fenn, G. K., and LeRoy, G. V., J. Amer. med. Ass. 1940, 115, 1962.

2 Buchbinder, W. C., Proc. Soc. exp. Biol. (N.Y.), 1929-30, 27, 542.

3 McLemore, G. A., and Levinc, S. A., Amer. J. med. Sci., 1955, 229, 386.

\section{Asian Influenza}

SIR,-The recent Asian pandemic of influenza has passed through India and seems to have proceeded to Western countries. Epidemiological observations have revealed that the new Asian influenza is as infectious as that of the last pandemic of influenza in 1918-19, but the killing power of Asian influenza has fallen off. Thus unusually high attack rates have been noted, with an average estimated at $19 \%$ in the Philippines, although in individual communities higher attack rates have been reported. But mortality rates have been less than 1 per 1,000 cases. These deaths were usually in infants and debilitated persons. ${ }^{1}$

In India there were $1,889,825$ cases and 536 deaths up to the middle of July, $1957 .^{2}$ In view of the low mortality rate, it has been suggested in many quarters that the current Asian strain of influenza virus, determined as a variant of type $\mathbf{A}$, has lost its malignancy as a result of mutation which may be due to the effect of radiation from recent nuclear tests. The much improved prognosis of Asian influenza cannot be attributed to the mutation theory alone. It must be remembered that when one compares the frequency and case fatality of influenza now with those of thirty-eight years ago one is not really comparing the actual frequency of the disease but the frequency with which the term "influenza" is used to describe a disease status by observers differing in their education and medical outlook over a period of thirty-eight years.

We should not forget that the influenza virus acts synergistically with various bacteria to produce terminal pneumonia, bronchopneumonia, etc., and the advent of 